Soraya N. Joson, MD

Natividad A. Almazan, MD

Melanie Grace Y. Cruz, MD

Department of Otorhinolaryngology

Head and Neck Surgery

East Avenue Medical Center

Correspondence: Dr. Melanie Grace Y. Cruz

Department of Otorhinolaryngology

Head and Neck Surgery

6th Floor, East Avenue Medical Center

East Avenue, Diliman, Quezon City 1100

Philippines

Phone: (632) 9280611 local 324

Fax: (632) 4356988

Email: eamc_enthns@yahoo.com

The authors declared that this represents original material that is not being considered for publication or has not been published or accepted for publication elsewhere in full or in part, in print or electronic media; that the manuscript has been read and approved by all the authors, that the requirements for authorship have been met by each author, and that each author believes that the manuscript represents honest work.

Disclosures: The authors signed disclosures that there are no financial or other (including personal) relationships, intellectual passion, political or religious beliefs, and institutional affiliations that might lead to a conflict of interest.

Presented at the Philippine Society of Otolaryngology Head and Neck Surgery Interesting Case Contest (3rd Place), June 30, 2016. Unilab Bayanihan Center, Pasig City

\title{
An Impacted Live Fish in the Oropharynx of an 8-Year-Old Child
}

\begin{abstract}
Objective: To present an atypical case of a live fish lodged in the throat of a pediatric patient and
\end{abstract} discuss its management.

\section{Methods:}

Design: Case Report

Setting: Tertiary Government Hospital

Patient: One

Result: An 8-year-old girl swallowed a live fish when she accidentally fell in a body of water. Failed attempts to remove the live fish prompted consult in the emergency room of our hospital, where removal of the foreign body was successfully done using Mixter right angle forceps assisted with a gloved finger. Transient cyanosis and unresponsiveness during extraction was overcome with oxygen by mask and she regained consciousness. She was allowed to go home as no other untoward events or complications were observed.

Conclusion: All ingested foreign bodies particularly in children require immediate attention. The survival of patients with upper aerodigestive and airway foreign bodies depends on early recognition and prompt multidisciplinary management.

Keywords: Foreign body, endoscopy, foreign body ingestion, impaction, oropharynx

While swimming in the river, a person can accidentally swallow water. But how often do we see a fish enter the mouth and get lodged in the oropharyngeal inlet? We report a rare case of live fish impaction in the oropharynx of a pediatric patient and discuss its removal.

\section{CASE REPORT}

An 8-year-old girl was brought to the emergency room of our hospital with severe throat discomfort. Her parents claimed that she was walking along the banks of a river in Bulacan in central Luzon, Philippines, when she slipped and accidently fell into the water. A live fish swam towards her and accidentally entered her mouth. Attempts to remove the fish from her mouth were unsuccessful and she was rushed to our hospital where she arrived approximately 8 hours after the incident. 
She was received conscious and was able to follow commands but noted to have dysphagia, odynophagia, drooling of saliva and a muffled voice. Oral examination revealed abrasions and hyperemia over the soft palate, with the dark-colored fin of the fish visible in the oropharynx. (Figure 1) This was better visualized with depression of the tongue. Extraction of the foreign body was initially planned under sedation, but the anesthesiologist was concerned about the risk of

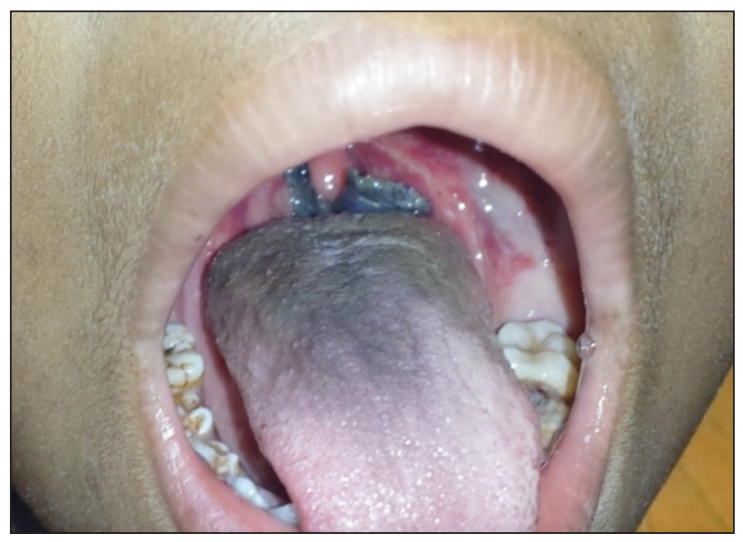

Figure 1. Abrasions over the soft palate with the fish's tail seen in the oropharynx.

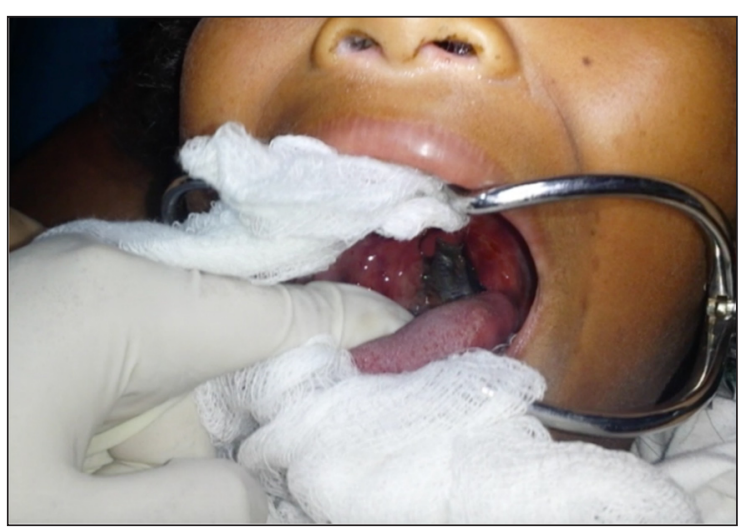

Figure 2. Application of Jennings retractor, and depression of the tongue with a gloved finger reveals more of the fish.



Figure 3. $8 \times 5 \mathrm{~cm}$ fish. A part of the tail was detached during initial extraction attempts. complete airway obstruction from the tongue falling back against the already-obstructed airway in our patient who was becoming cyanotic and lethergic. Consent was obtained to remove it while she was awake and a Jennings mouth gag was applied to hold her mouth open. (Figure 2) Initial attempts to remove the fish using Mixter right-angle forceps were unsuccessful, as were subsequent attempts made by palpating the fish with a gloved finger. The fish was eventually grasped mid-body using Mixter right-angle forceps assisted by a gloved finger and finally extracted, measuring $8 \times 5 \mathrm{~cm}$. (Figure 3) Immediately prior to extraction of the foreign body, the child became cyanotic and unresponsive. Oxygen was administered by mask and she immediately regained consciousness. There was no bleeding noted in the oropharynx. They declined admission for observation, and were eventually allowed to go home, as there were no other untoward events or complications.

\section{DISCUSSION}

Foreign body ingestion among children is not uncommon in the emergency room. Majority of these were ingested accidentally among children aged between six months and six years. ${ }^{1,2}$ Foreign bodies may be aspirated or impacted. Common sites of impaction include the tonsils, base of the tongue, piriform fossae and the cricopharynx. ${ }^{3}$ However, a bigger foreign body in the throat may block both the trachea and esophagus and result in death. With impaction, our patient had dysphagia, odynophagia, drooling of saliva and muffling of the voice. In most cases of foreign bodies in children, diagnosis may be difficult because a clear history cannot be obtained due to the lack of characteristic clinical features and radiologic findings. ${ }^{3}$ It was different in our patient. Oral examination revealed a large fish obstructing the entire oropharynx. Impaction of live fish in the laryngopharynx has been previously reported in adults and in children, ${ }^{4,5}$ but to the best of our knowledge not in our institution.

An impacted foreign body in the oropharynx should be immediately removed as the chance of spontaneous passage is less likely. A delay in the procedure causes edema of the mucosa which lodges the object more firmly, making later manipulation extremely difficult. ${ }^{6}$ More serious and potential life-threatening complications include esophageal perforation, mediastinitis, cervical or mediastinal abscess, emphysema, esophageal-tracheal fistula and septic complications. ${ }^{2}$ Removal should be performed promptly as no foreign body should remain in the aerodigestive tract beyond 24 hours after presentation.? Most importantly, the procedure should be performed under conditions of maximum safety and minimum trauma. ${ }^{6}$

Live fish entering the pharynx while bathing in a stream of water is not commonly reported. In a search of HERDIN, PubMed and Google Scholar using the keywords "foreign body," "impaction," "oropharynx," 


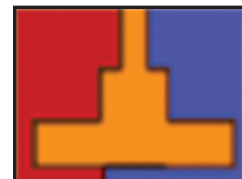

CASE REPORTS

PIOHKS

Philippine Journal Of Otolaryngology-Head And Neck Surgery

VOL. 32 No. 1 JANUARY - JUNE 2017

"hypopharynx," "esophagus," and "fish" the authors did not find any similar cases reported in the Philippines. However, live fish impaction in the hypopharynx in both children and adults have been reported elsewhere. ${ }^{4,5}$ Most notable was the report of a live fish successfully removed in toto from the hypopharynx of a 7-month-old child. ${ }^{4}$ Removal was done under general anesthesia inside the operating room. Although we operated under less-controlled circumstances, we also obtained a successful outcome. Ideally, patients should be relaxed, well ventilated and unconscious as these factors afford the best prospects for the successful removal of the foreign body. Our decision to remove the foreign body promptly in the emergency room was further necessitated because the patient was becoming cyanotic and lethargic. The possible complications of awake foreign body removal in this case were deemed to outweigh the risk of her possible impending demise.

This interesting rare case of impacted live fish in the oropharynx was, to the best of our knowledge, the first in our institution and the first reported in the Philippines. The decision to extract the fish was urgent and straightforward because of the risk of total airway obstruction. All ingested foreign bodies, particularly in children, require immediate attention, and impacted oropharyngeal foreign bodies in particular should be removed. The survival of patients with upper aerodigestive and airway foreign bodies depends on early recognition and prompt multidisciplinary management.

\section{REFERENCES}

1. Mevio E, Mevio N. Unusual esophageal foreign body: A table fork. Case Rep Otolaryngol. [Internet]. 2013; 2013:987504: 1-20 [cited 2015 Dec 15]. Available from: https://www.hindawi. com/journals/criot/2013/987504/. DOI: 10.1155/2013/987504; PMID: 23634316; PMCID: PMC3619629.

2. Sardana $P$, Bais AS, Singh VP, Arora M. Unusual foreign bodies of the aerodigestive tract. Indian J Otolarygol Head Neck Surg. 2002 Apr; 54(2): 123-126. DOI: 10.1007/BF02968730; PMID: 23119872; PMCID: PMC3450538.

3. Vadhera R, Gulati SP, Garg A, Goyal R, Ghai A. Extraluminal hypopharyngeal foreign body. Indian J Otolarygol Head Neck Surg. 2009 Mar; 61(1):76-78. DOI: 10.1007/s12070-009-0039-Z; PMID: 23120609; PMCID: PMC3450132.

4. Aggarwal MK, Singh GB, Dhawan R, Tiwari A. An unusual case of live fish impaction in hypopharynx in an infant. Int J Pediatr Otorhinolaryngol. 2006 Jun; 1(2): 154-156.

5. Senthilkumaran S, Sweni S, Ganapathysubramanian, Suresh P, Thirumalaikolundusubramnian P. Live fish impaction in hypopharynx in an elderly patient. Int J Gerontol. 2011 Dec; 5(4): 225-226. DOI:: http://dx.doi.org/10.1016/j.ijge.2011.12.003.

6. Murty P, Ingle VS, Ramakrishna S, Shah FA, Varghese P. Foreign bodies in the upper aero-digestive tract. J Sci Res Med Sci. 2001 Oct; 3(2): 117-120. PMID: 24019718; PMCID: PMC3174712.

7. Loh KS, Tan LK, Smith JD, Yeoh KH, Dong F. Complications of foreign bodies in the esophagus. Otolaryngol Head Neck Surg. 2000 Nov; 123(5):613-616. DOI: 10.1067/mhn.2000.110616; PMID: 11077351 